\title{
Investigation of Stressors Affecting a sample of Pharmacy Students and the Coping Strategies Employed using Modified Academic Stressors Scale and Brief Cope Scale: a Prospective Study
}

\author{
Aaseer Thamby Sam, ${ }^{*}$ Bharathi Muttusamy, ${ }^{1}$ Sum Mun Yee, ${ }^{1}$ Thineswary Ayapanaido ${ }^{1}$ and Subramani Parasuraman ${ }^{2}$ \\ 'Unit of Pharmacy Practice, Faculty of Pharmacy, AIMST University, Kedah Darul Aman, MALAYSIA. \\ 2Unit of Pharmacology, Faculty of Pharmacy, AIMST University, Kedah Darul Aman, MALAYSIA.
}

\begin{abstract}
Objective: To study the relationship between perceived stress, health outcomes of different batches of pharmacy students. Methodology: A total of 320 undergraduate pharmacy students in AIMST University were included in the study. Voluntary participation was mandatory and Informed Consent Forms were provided to each participant, prior to answering selfadministered questionnaires, which were distributed in two phases. A prospective cross-sectional correlation design used o examines correlations between perceived stress, physical activity, and other health behaviors in pharmacy students. Results: Frequencies and descriptive data analysis was done and statistical difference between the phases were calculated using one-way ANOVA followed by Tukey's post hoc test. A few stressors [mid-semester and final examinations; study break periods; grades acquired (GPA and CGPA); financial issues] showed significant variations. The two-tailed unpaired t-test revealed significant changes in stress levels and responses between both phases, possibly due to the timing of each phase (before mid-sem exams and after mid-sem exams). A worrying aspect was the increase in negative coping strategies in many categories. Conclusion: Stressors and stressful events do have a major impact on a student's academic and extra-curricular life. Managing stress in a positive manner helps to cope appropriately with stress and enable each student to face life's future stressful situations in a prepared manner. The modified study instrument used in this study explored various dimensions of stress (general stressors, test anxiety stressors, stressful events checklist and stress coping strategies). It is a beneficial tool for evaluating students' stress levels and to take appropriate remedial measures.
\end{abstract}

Key words: Stress, Positive and Negative stressors, Academic Stressors scale, Brief COPE scale, Optimal stress, Positive coping strategies.

\section{PICTORIAL ABSTRACT}

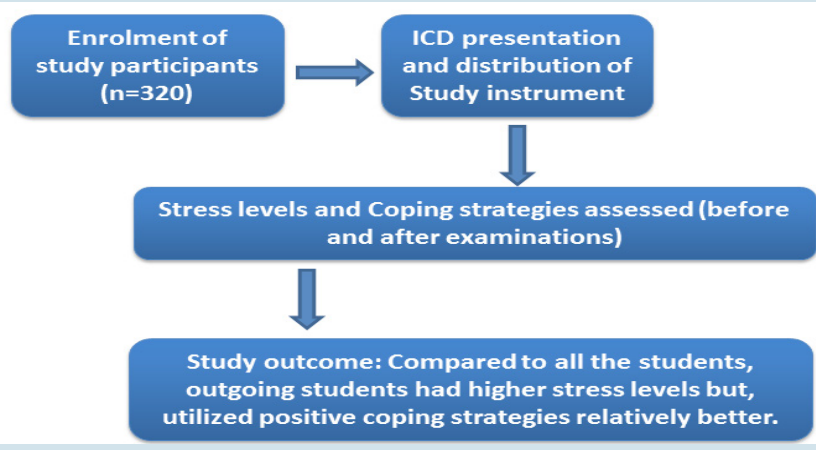

Correspondence:

Aaseer Thamby Sam,

Unit of Pharmacy Practice, Faculty of Pharmacy, AIMST University,

Kedah Darul Aman, MALAYSIA. Phone no: +60 4-429 8000

E-mail: samthamby@gmail.com

DOI: 10.5530/jyp.2016.2.12

\section{INTRODUCTION}

Stress can be described as "physical, mental, or emotional strain or tension" as well as "a condition or feeling experienced when a person perceives that demands exceed the personal and social resources the individual is able to mobilize". ${ }^{1}$ University students, however, often experience an undue amount of stress, which can have negative academic, emotional, or health outcomes. ${ }^{2}$ This can occur at different time periods during a semester or years in college, during the transition from undergraduate to professional or graduate programs, or upon graduation. A dramatic increase in student stress is an alarming trend in college student health nationwide, as nearly $80 \%$ of students report being moderately stressed or burned out. ${ }^{3-4}$ Since stress is known to have detrimental effects on the physical and mental wellbeing of students, ${ }^{5}$ intervention is needed by assessing perceived stress in college students and determining its effect on depression in order to establish ways to decrease the risk and rate of depression.

The workload during pharmacy education programme is inherently stressful and demanding. Stress and depression have been consistently linked to mental and physical health effects. ${ }^{1}$ An optimal level of stress enhances learning while excess of stress can cause health problems. This results in reduction of students' self-esteem and affects their academic achievement. Stress in university students has many sources, including academics, personal situations, environment, time, and economic circumstances. ${ }^{6,7}$ This is due to its capability in modifying and altering various features of the immune response such as making people vulnerable to increasing their susceptibility to infections, increasing their risk for upper respiratory tract infections (URTI) and triggering inflammatory responses leading to more colds and sickness in times of stress. ${ }^{8}$ The modified study instrument used was sourced from the Academic Stressors Scale (describing the stress in the respondents' institution/college life from the various sources) and the Brief COPE scale (a shortened version of the original COPE scale, dealing with ways people cope with the stresses in their lives)..$^{9,10}$ The different student stress factors are depicted in Figure 1. The significant positive relationship between perceived stress and health status in college students and the influence of positive coping strategies remains unclear. Hence thiscross-sectional correlation study is planned to determine the relationship between perceived stress and potential depression in college students.

\section{METHODOLOGY}

\section{Participants}

A total of 405 undergraduate pharmacy students from AIMST University were enrolled in the study and 320 students participated. The written in- 


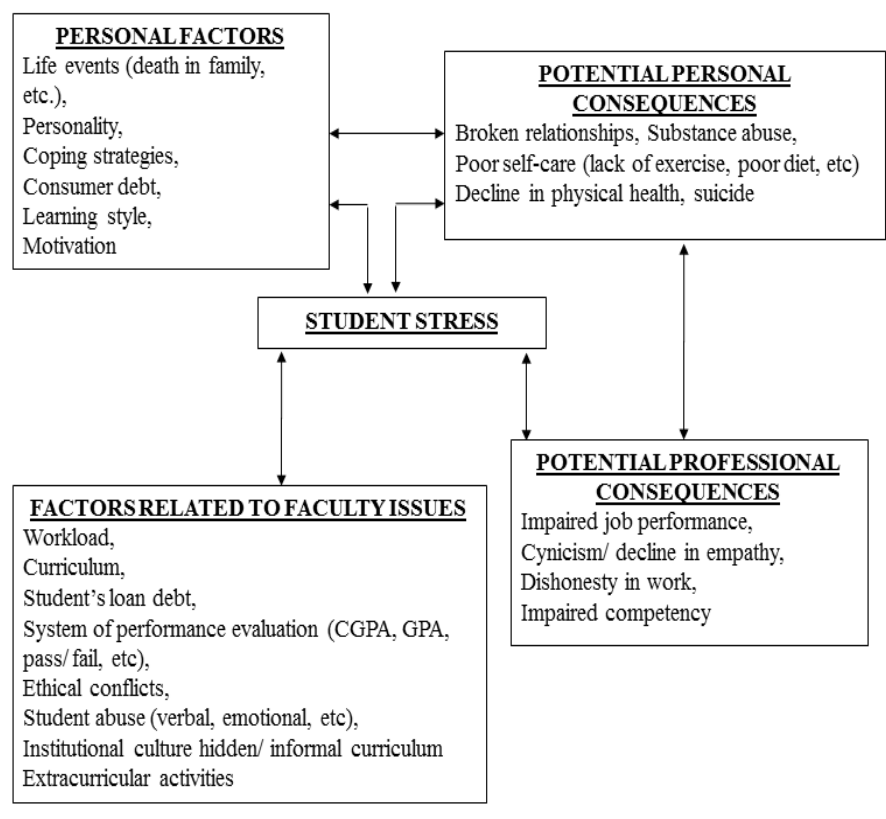

Figure 1: Classification of different student stress factors

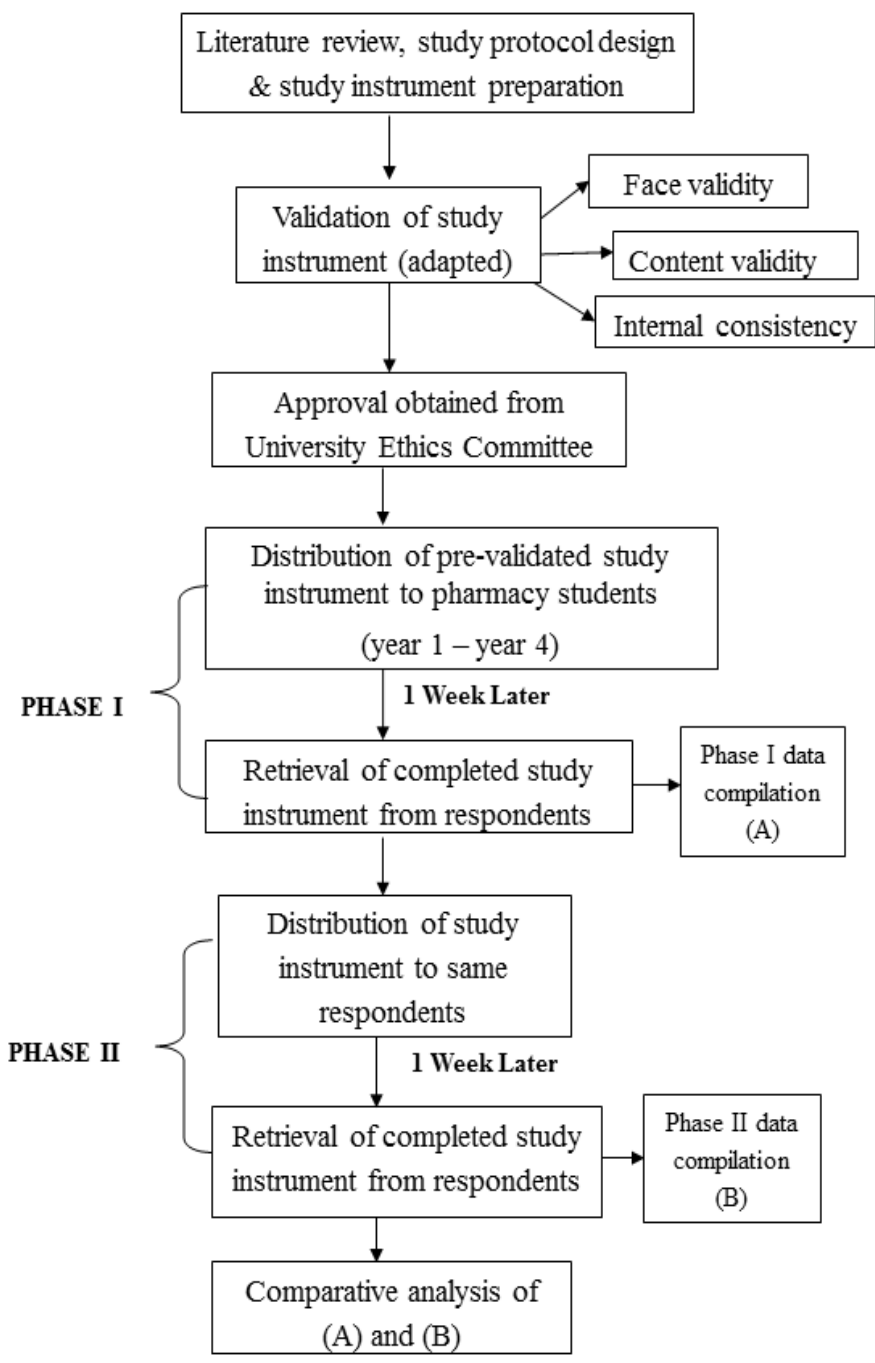

Figure 2: Requirement, allocation and follow-up of participants
Table 1: Summary of academic stressors' levels of undergraduate pharmacy students

\begin{tabular}{ccccc}
\hline YEAR & Year 1 & Year 2 & Year 3 & Year 4 \\
\hline No. of students & 78 & 81 & 86 & 75 \\
Age range (years) & $20-27$ & $21-28$ & $22-36$ & $23-28$ \\
Average age (years) & 20 & 22 & 23 & 24 \\
Gender ratio(M:F) & $16: 62$ & $28: 53$ & $24: 62$ & $14: 61$ \\
\hline
\end{tabular}

formed consent was obtained from the study participants. The study was approved by the AIMST University Human and Animal Ethics committee and the study was conducted according the CONSORT guidelines.

\section{Study Design and Procedures}

A prospective cross-sectional correlation design was used to examine correlations between perceived stress, physical activity, and other health behaviors in pharmacy students. The self-administered questionnaires were distributed to the various batches during two different phases in the semester (prior to the mid-semester examinations and a month after the mid-semester examinations), as depicted in Figure 2. Each questionnaire was coded by the researchers, to ensure respondents' confidentiality.

\section{Study Instrument}

The study instrument employed was created by modifying the Academic Stressors Scale and Brief COPE Scale. The study instrument contains two sections to access the academic stressors' levels (section A) and coping strategies (section B). The study instrument was validated by the peers and pilot study was conducted using 20 volunteers to calculate the Cronbach-alpha value. The Cronbach-alpha of pilot study was 0.71 , indicating that the study instrument was reliable for use in the current study.

\section{Statistical Analysis}

All data were analyzed using Statistical Package for Social Sciences (SPSS for Windows, Version 16.0). Frequencies and descriptive data analysis was done and statistical difference between the phases were calculated using one-way ANOVA followed by Tukey's post hoc test.

\section{RESULT}

Totally 320 subjects participated in the study. The demographic details of the study subjects are summarized in Table 1 The summaries of academic stressors, positive and negative coping strategies are displayed in Tables 2, 3 and 4 respectively. Majority of the students have increased stress levels in the domains pertaining to examinations, which comprise mid-semester and final examinations, study break periods and the grades acquired (GPA and CGPA). Stress induced by financial issues was observed most among pre-final year students. Data from the pre-final year students showed significant changes in stress levelsattributed to late arrival to class, assignments and quizzes. Overall, the final year followed pre-final year students have more stress levels compare to that of years 1 and year 2 .

In coping with the stressors, the positive and negative strategies utilized by the students were almost on par with each other. Among year 1 students, statistical significance was observed in the negative coping methods ['making fun of stressful situations', 'saying to myself that the stressful event isn't real', and 'resorting to alcohol to relieve the stress levels']; and positive coping method ['trying to conceptualize a strategy to solve the issues/stress']. Among year 2 students, statistical significance was observed in the negative coping methods ['expressing negative feelings/thoughts repeatedly post-stressful situations', 'refusing to believe a stressful event occurred', and 'always blaming themselves for the stressful 
Table 2: Summary of academic stressors' levels of undergraduate pharmacy students

\begin{tabular}{|c|c|c|c|c|c|c|c|c|}
\hline \multirow{2}{*}{$\frac{\text { Section A/ year }}{\text { Stressors } \downarrow}$} & \multicolumn{2}{|c|}{ Year I } & \multicolumn{2}{|c|}{ Year II } & \multicolumn{2}{|c|}{ Year III } & \multicolumn{2}{|c|}{ Year IV } \\
\hline & Phase I & Phase II & Phase I & Phase II & Phase I & Phase II & Phase I & Phase II \\
\hline Classroom (environment) & $2.46 \pm 0.91$ & $2.67 \pm 1.12$ & $2.63 \pm 1.15$ & $2.31 \pm 0.98$ & $2.64 \pm 0.98$ & $2.27 \pm 0.58^{* *}$ & $2.48 \pm 1.09$ & $2.48 \pm 1.14$ \\
\hline Boring classes & $2.59 \pm 1.45$ & $2.92 \pm 1.34$ & $2.74 \pm 1.42$ & $2.48 \pm 1.19$ & $2.66 \pm 1.48$ & $2.01 \pm 0.77^{* * *}$ & $2.63 \pm 1.48$ & $2.69 \pm 0.90$ \\
\hline Fast paced lecturers & $3.26 \pm 1.06$ & $3.19 \pm 1.17$ & $3.20 \pm 1.31$ & $2.77 \pm 1.09^{*}$ & $3.17 \pm 1.15$ & $2.37 \pm 0.88^{* * *}$ & $2.85 \pm 1.23$ & $2.63 \pm 1.06$ \\
\hline Assignment(s) & $4.03 \pm 0.91$ & $3.59 \pm 1.14^{* *}$ & $3.75 \pm 1.11$ & $3.26 \pm 1.13^{* *}$ & $3.74 \pm 1.08$ & $2.57 \pm 0.83^{* * *}$ & $4.03 \pm 0.99$ & $2.68 \pm 1.03^{* * *}$ \\
\hline Unclear pronunciation by lecturer & $3.59 \pm 1.22$ & $3.51 \pm 1.17$ & $3.72 \pm 1.11$ & $3.32 \pm 0.99^{*}$ & $3.30 \pm 1.15$ & $1.67 \pm 0.66^{* * *}$ & $3.48 \pm 1.22$ & $2.59 \pm 1.16^{* * *}$ \\
\hline $\begin{array}{l}\text { Unprepared to respond to questions by } \\
\text { lecturer }\end{array}$ & $3.64 \pm 0.94$ & $3.42 \pm 1.16$ & $3.74 \pm 1.01$ & $3.63 \pm 0.95$ & $3.69 \pm 1.03$ & $1.55 \pm 0.61^{* * *}$ & $3.85 \pm 1.12$ & $2.64 \pm 1.19^{* * *}$ \\
\hline Practical exams \& viva & $4.36 \pm 0.87$ & $3.64 \pm 1.16^{* * *}$ & $4.22 \pm 0.94$ & $4.15 \pm 0.84$ & $4.26 \pm 0.94$ & $2.84 \pm 0.81^{* * *}$ & $4.48 \pm 0.79$ & $2.93 \pm 1.11^{* * *}$ \\
\hline Mid-sem theory exams & $4.24 \pm 0.91$ & $3.74 \pm 1.21^{* *}$ & $4.00 \pm 1.06$ & $4.32 \pm 0.89^{*}$ & $4.16 \pm 0.96$ & $2.84 \pm 0.88^{* * *}$ & $4.56 \pm 0.72$ & $3.13 \pm 0.93^{* * *}$ \\
\hline Semester practical exams & $4.18 \pm 0.94$ & $3.72 \pm 1.22^{* *}$ & $4.04 \pm 1.05$ & $4.40 \pm 0.86^{*}$ & $4.16 \pm 0.98$ & $2.93 \pm 0.84^{* * *}$ & $4.36 \pm 0.78$ & $3.32 \pm 0.96^{* * *}$ \\
\hline Studying for final examinations & $4.50 \pm 0.83$ & $3.78 \pm 1.14^{* * *}$ & $4.31 \pm 1.04$ & $4.41 \pm 0.89$ & $4.50 \pm 0.79$ & $3.85 \pm 0.93^{* * *}$ & $4.55 \pm 0.84$ & $3.27 \pm 1.03^{* * *}$ \\
\hline Study break duration (mid-sem, finals) & $4.21 \pm 0.92$ & $3.83 \pm 1.20^{*}$ & $3.98 \pm 1.25$ & $4.16 \pm 1.10$ & $3.87 \pm 1.21$ & $3.77 \pm 0.95$ & $4.03 \pm 1.08$ & $3.25 \pm 1.07^{* * *}$ \\
\hline Final exam and grades(GPA,CGPA) & $4.29 \pm 1.02$ & $3.73 \pm 1.17^{* *}$ & $4.15 \pm 1.09$ & $4.32 \pm 1.03$ & $4.13 \pm 1.03$ & $4.27 \pm 0.80$ & $4.55 \pm 0.89$ & $3.39 \pm 1.10^{* * *}$ \\
\hline Mentor-mentee sessions & $2.00 \pm 0.98$ & $3.19 \pm 1.40^{* * *}$ & $2.30 \pm 1.04$ & $2.20 \pm 1.25$ & $2.13 \pm 1.11$ & $2.53 \pm 0.70^{* *}$ & $2.61 \pm 1.36$ & $2.85 \pm 1.02$ \\
\hline Relationship issues & $2.28 \pm 1.13$ & $2.49 \pm 1.24$ & $2.23 \pm 1.13$ & $2.02 \pm 1.12$ & $2.21 \pm 1.08$ & $1.98 \pm 0.75$ & $2.25 \pm 1.22$ & $2.67 \pm 1.09$ \\
\hline Family issues & $1.96 \pm 1.07$ & $2.41 \pm 1.29^{*}$ & $2.16 \pm 1.17$ & $2.11 \pm 1.21$ & $2.00 \pm 1.05$ & $1.66 \pm 0.64^{*}$ & $1.97 \pm 1.11$ & $2.39 \pm 1.15^{*}$ \\
\hline Financial issues & $2.63 \pm 1.19$ & $2.38 \pm 1.21$ & $2.69 \pm 1.34$ & $2.25 \pm 1.28$ & $2.76 \pm 1.26$ & $1.80 \pm 0.67^{* * *}$ & $2.56 \pm 1.21$ & $2.49 \pm 1.16$ \\
\hline
\end{tabular}

All the values are mean $\pm \mathrm{SD}$ of $\mathrm{N}^{*}\left({ }^{*} \mathrm{Y} 1=78 ; \mathrm{Y} 2=81 ; \mathrm{Y} 3=86\right.$ and $\left.\mathrm{Y}=75\right) .{ }^{*} \mathrm{P}<0.05 ;{ }^{*} \mathrm{P}<0.01$ and ${ }^{* *} \mathrm{P}<0.001$ compared with phase I. Data were analyzed using one-way ANOVA followed by Tukey's post hoc test.

Table 3: Negative coping strategies by undergraduate pharmacy students (customized Brief COPE scale)

\begin{tabular}{|c|c|c|c|c|c|c|c|c|}
\hline \multirow[t]{2}{*}{ Section D/ year } & \multicolumn{2}{|c|}{ Year I } & \multicolumn{2}{|c|}{ Year II } & \multicolumn{2}{|c|}{ Year III } & \multicolumn{2}{|c|}{ Year IV } \\
\hline & Phase I & Phase II & Phase I & Phase II & Phase I & Phase II & Phase I & Phase II \\
\hline $\begin{array}{l}\text { Expressing my negative feelings } \\
\text { post-stressful situations. }\end{array}$ & $2.94 \pm 0.98$ & $2.99 \pm 1.17$ & $2.81 \pm 0.94$ & $2.44 \pm 1.17^{*}$ & $2.81 \pm 1.01$ & $2.78 \pm 0.80$ & $2.95 \pm 1.22$ & $2.76 \pm 1.23$ \\
\hline $\begin{array}{l}\text { Refusing to believe that a stressful } \\
\text { event has happened. }\end{array}$ & $2.81 \pm 0.98$ & $3.13 \pm 1.07$ & $2.57 \pm 1.06$ & $2.20 \pm 1.02^{*}$ & $2.10 \pm 0.98$ & $2.48 \pm 0.98^{*}$ & $2.28 \pm 1.01$ & $2.73 \pm 1.08^{* *}$ \\
\hline $\begin{array}{l}\text { Giving up trying to deal with a } \\
\text { stressful situation/event. }\end{array}$ & $2.64 \pm 1.03$ & $2.94 \pm 1.19$ & $2.47 \pm 1.00$ & $2.35 \pm 1.01$ & $2.37 \pm 0.97$ & $2.49 \pm 1.19$ & $2.33 \pm 0.98$ & $2.68 \pm 1.18^{*}$ \\
\hline $\begin{array}{l}\text { Saying to myself 'this stressful } \\
\text { event isn't real. }\end{array}$ & $2.31 \pm 0.97$ & $2.99 \pm 1.11^{\star * *}$ & $2.20 \pm 1.07$ & $2.22 \pm 1.01$ & $2.08 \pm 0.97$ & $2.29 \pm 0.96$ & $2.21 \pm 1.07$ & $2.81 \pm 1.20^{* * *}$ \\
\hline $\begin{array}{l}\text { Making fun of the stressful } \\
\text { situation. }\end{array}$ & $2.69 \pm 1.19$ & $3.15 \pm 1.11^{*}$ & $2.72 \pm 1.24$ & $2.49 \pm 1.09$ & $2.56 \pm 1.21$ & $1.57 \pm 0.66^{* * *}$ & $2.68 \pm 1.18$ & $2.47 \pm 1.07$ \\
\hline Criticizing myself. & $2.95 \pm 1.16$ & $3.27 \pm 1.02$ & $2.69 \pm 1.10$ & $2.35 \pm 1.24$ & $2.85 \pm 1.16$ & $1.50 \pm 0.68$ & $3.01 \pm 1.34$ & $2.61 \pm 1.15^{*}$ \\
\hline $\begin{array}{c}\text { Blaming myself for things that } \\
\text { happen. }\end{array}$ & $2.99 \pm 1.03$ & $3.03 \pm 1.14$ & $2.90 \pm 1.10$ & $2.00 \pm 1.12^{* * *}$ & $2.73 \pm 1.09$ & $2.06 \pm 0.71^{* * *}$ & $3.00 \pm 1.25$ & $2.60 \pm 0.99^{*}$ \\
\hline $\begin{array}{l}\text { Using alcohol or other substances } \\
\text { to make myself feel better. }\end{array}$ & $1.42 \pm 0.92$ & $2.63 \pm 1.40^{* * *}$ & $1.31 \pm 0.71$ & $1.44 \pm 0.82$ & $1.38 \pm 0.92$ & $1.84 \pm 0.75^{* * *}$ & $1.33 \pm 0.74$ & $1.81 \pm 0.95^{\star * *}$ \\
\hline
\end{tabular}

All the values are mean $\pm \mathrm{SD}$ of $\mathrm{N}^{*}\left({ }^{*} \mathrm{Y} 1=78 ; \mathrm{Y} 2=81 ; \mathrm{Y} 3=86\right.$ and $\left.\mathrm{Y}=75\right) .{ }^{*} \mathrm{P}<0.05 ;{ }^{* *} \mathrm{P}<0.01$ and ${ }^{* * *} \mathrm{P}<0.001$ compared with phase I. Data were analyzed using one-way ANOVA followed by Tukey's post hoc test. 
THAMBY SAM et al::Assessment of stress levels and coping using academic stressors scale and COPE scale

Table 4: Positive coping strategies by undergraduate pharmacy students (customized Brief COPE scale)

\begin{tabular}{|c|c|c|c|c|c|c|c|c|}
\hline \multirow[t]{2}{*}{ Section D/year } & \multicolumn{2}{|c|}{ Year I } & \multicolumn{2}{|c|}{ Year II } & \multicolumn{2}{|c|}{ Year III } & \multicolumn{2}{|c|}{ Year IV } \\
\hline & Phase I & Phase II & Phase I & Phase II & Phase I & Phase II & Phase I & Phase II \\
\hline Praying or meditating. & $3.04 \pm 1.19$ & $3.29 \pm 1.11$ & $3.02 \pm 1.31$ & $3.42 \pm 1.39$ & $2.94 \pm 1.30$ & $1.49 \pm 0.70^{* * *}$ & $3.14 \pm 1.38$ & $2.48 \pm 1.11^{\star * *}$ \\
\hline $\begin{array}{l}\text { Thinking hard about what step } \\
\text { to take. }\end{array}$ & $3.53 \pm 0.95$ & $3.31 \pm 1.12$ & $3.31 \pm 1.01$ & $3.80 \pm 1.01^{* *}$ & $3.49 \pm 0.95$ & $3.08 \pm 0.91^{* *}$ & $3.73 \pm 1.06$ & $2.57 \pm 1.07^{* * *}$ \\
\hline $\begin{array}{l}\text { Learning to live with the } \\
\text { consequences of the stressful } \\
\text { situation. }\end{array}$ & $3.46 \pm 0.98$ & $3.28 \pm 1.03$ & $3.40 \pm 0.90$ & $3.67 \pm 1.05$ & $3.59 \pm 1.00$ & $3.09 \pm 0.71^{\star * *}$ & $3.89 \pm 0.94$ & $2.84 \pm 0.96^{* * *}$ \\
\hline $\begin{array}{l}\text { Getting comfort and } \\
\text { understanding from someone. }\end{array}$ & $3.36 \pm 0.91$ & $3.44 \pm 0.97$ & $3.09 \pm 0.92$ & $3.54 \pm 1.00^{* *}$ & $3.69 \pm 0.95$ & $4.43 \pm 0.88^{* * *}$ & $3.92 \pm 0.94$ & $3.05 \pm 1.22^{* * *}$ \\
\hline $\begin{array}{l}\text { Accepting the reality of the fact } \\
\text { that it has happened. }\end{array}$ & $3.63 \pm 0.91$ & $3.33 \pm 1.06$ & $3.84 \pm 1.01$ & $3.54 \pm 1.14$ & $3.79 \pm 1.01$ & $2.80 \pm 0.79^{* * *}$ & $4.21 \pm 0.84$ & $2.75 \pm 1.14^{\star * *}$ \\
\hline $\begin{array}{c}\text { Getting emotional support from } \\
\text { others. }\end{array}$ & $3.01 \pm 0.95$ & $3.21 \pm 1.12$ & $3.12 \pm 1.09$ & $2.69 \pm 1.23^{*}$ & $3.47 \pm 1.03$ & $4.19 \pm 1.08^{* * *}$ & $3.77 \pm 1.13$ & $2.76 \pm 1.23^{* * *}$ \\
\hline $\begin{array}{l}\text { Trying to come up with a strategy } \\
\text { about what to do. }\end{array}$ & $3.54 \pm 0.89$ & $3.14 \pm 1.09^{*}$ & $3.43 \pm 0.97$ & $3.00 \pm 1.27^{\star}$ & $3.56 \pm 0.88$ & $2.81 \pm 0.56^{* * *}$ & $3.87 \pm 0.89$ & $2.88 \pm 1.05^{* * *}$ \\
\hline
\end{tabular}

All the values are mean $\pm \mathrm{SD}$ of $\mathrm{N}^{*}\left({ }^{*} \mathrm{Y} 1=78 ; \mathrm{Y} 2=81 ; \mathrm{Y} 3=86\right.$ and $\left.\mathrm{Y}=75\right) .{ }^{\star} \mathrm{P}<0.05 ;{ }^{*} \mathrm{P}<0.01$ and ${ }^{* *} \mathrm{P}<0.001$ compared with phase $\mathrm{I}$. Data were analyzed using one-way ANOVA followed by Tukey's post hoc test.

event']; and positive coping methods ['seeking comfort and understanding from someone', 'thinking hard about the right way to solve the issue, 'trying to conceptualize a strategy to solve the issues/stress']. Among year 3 students, statistical significance was observed in the negative coping methods ['making fun of stressful situations', 'saying to myself that the stressful event isn't real', and 'resorting to alcohol to relieve the stress levels']; and positive coping methods ['seeking comfort and understanding from someone', 'thinking hard about the right way to solve the issue, 'trying to conceptualize a strategy to solve the issues/stress', 'living with the consequences of the stressful event']. Among year 4 students, statistical significance was observed in the negative coping methods ['giving up trying to deal with a stressful event', 'saying to myself that the stressful event isn't real', 'self-criticism' and 'resorting to alcohol to relieve the stress levels']; and positive coping methods ['seeking comfort and understanding from someone, 'thinking hard about the right way to solve the issue,' 'trying to conceptualize a strategy to solve the issues/stress', 'living with the consequences of the stressful event' and 'praying or meditating to respond calmly to the stressful event'].

\section{DISCUSSION}

Excessive stress interferes with the person's ability to function normally. According to Spielberger, states of anxiety are characterized by subjective feelings of nervousness, worry, tension, or apprehension, andby arousal of the autonomic nervous system (i.e., sweating, heart palpitation, muscle tension). Excessive anxiety also interferes with the person's ability to function normally. ${ }^{11}$ Any level of stress, if left unattended, can lead to sleeping disorders, burnout, a drop out, a fact presented by Dyrbye et al. in their numerous studies. ${ }^{12,13}$ Stress sources include programme curriculum, examination, assignments, pop-quizzes, PBLs, viva-voce, practical exams, presentations (journal club, research), personal competence, endurance and time spent outside medical school. Increase in concerns or stressors correlated with an increase in depression and anxiety.

From this study, section-Aof the questionnaire focused on general academic stressors during the student life. There were significant statistical differences in these domains: presentations in class by the students; mid-semester theory exams; and mentor-mentee sessions. The above data indicate the results where significant variations in the stressors were felt during phases-I and II in each batch. From these, there were a few areas where (statistically), the stressors showed increase in phase-II, as in late dismissal of classes-possibly affecting the upcoming classes; mid sem theory exams-this could be maybe that the overall performance is Y2 was quite low comparatively, and this could affect the students' preparation for the final exams; poor performances academically could explain the variations in Y1 and Y3 students in A19 stressor; familial issues were predominant stressors in $\mathrm{Y} 1$ and $\mathrm{Y} 4$ students.

After a student graduates from high school and moves away from home, he or she is often out of their comfort zone. Stress develops during this transition as the student tries to adjust to the new situations and adapt to a new college environment. ${ }^{4}$ Learning to cope properly with distress and eustress is important, as the behaviors established in college can continue for years or even a lifetime. ${ }^{14}$ If behaviors and habits resulting from stress management are maladaptive, they may have both psychologically and physiologically detrimental effects on the body and mind. ${ }^{3}$ It is important to address what influences health behaviors have on the relationship between perceived stress and depression in order to help prevent harmful health outcomes in the future. ${ }^{14}$ Students react to university in a variety of ways. For some, university can be stressful if they were away from their homes and families. Living in the university student accommodation, in private accommodation or with relatives is another source of stress. The presence of excessive physical and/or emotional stress in the university student life can leave the resources of the immune system depleted, which may affect the immune system ability to cope with such changes leading to different immune-mediated diseases such as cold, flu, sore throat, hair and skin disorders. ${ }^{15,16}$

Section-B pertains to coping strategies by individuals dealing with stressful situations. Coping strategies can either be positive (praying, emotional support, strategizing etc.), or negative (negative expressions, self-criticisms, alcoholism etc.). There were increases in positive coping strategies in each batch (depicted statistically). However, a worrying aspect was the identification of increases in certain negative coping strategies. These strategies are not beneficial to any individual in the long-term. Efforts must be taken to highlight this issue and ensure that students resort to positive coping strategies to deal with stressors.

Positive coping strategies such as exercise and physical activity, addressing proper nutrition, acquiring an adequate amount of sleep, positive thinking, relaxation, meditationare also preferred by many. When stress is managed in positive ways, healthy outcomes of mental and physical well being 
(i.e. reduction in body tension, improved mental clarity, and increased well-being) are possible. ${ }^{17}$

The workload during pharmacy education programme is inherently stressful and demanding. Overwhelming burden of information leaves a minimal opportunity for the student to relax and recreate. Stress and depression have been consistently linked to mental and physical health effects. ${ }^{1}$ An optimal level of stress enhances learning while excess of stress can cause health problems. This results in reduction of students' self-esteem and affects their academic achievement. A high level of stress may have negative effect on cognitive functioning and learning of students in medical school. The young student population is vulnerable to stress of higher professional education due to competitive environment. ${ }^{9}$ A study by Henning et al., revealed pharmacy students suffer from more stress and distress than medical and dental students. ${ }^{18}$ Only one previous study by Gupchup et al., examined the relationship between pharmacy student stress levels and HRQOL. ${ }^{19}$ Sources and consequences of stress and their impact on various dimensions of HRQOL of pharmacy students warrant further investigation.

\section{LIMITATIONS OF THE STUDY}

- This type of study is short term, eliminating the possibility of observing perceived stress and the influence of health related behaviors over a long period of time for more appropriate results, as a longitudinal study typically provides.

- Being a correlational study, it cannot demonstrate causality.

- Stress affects everybody in various manners and each college student responds to stress differently. Some have more stress in their lives than others due to extreme or traumatic events. While some college students possess stress-resistant characteristics and are not greatly affected by stress compared to those who possess 'stress-prone characteristics'. This can alter how students rate and perceive their levels of stress in this study.

\section{CONCLUSION}

An optimal level of stress enhances learning, while excess of stress can cause health problems. This results in reduction of students' self-esteem and affects their academic achievement. A high level of stress may have negative effect on cognitive functioning and learning of pharmacy students. The young student population is vulnerable to stress of higher professional education due to competitive environment.

Stressors can impact students either in a positive or negative manner. Majority of students display the effects of stress, as evidenced by their decreased academic performance and extra-curricular activities. Our study focused on the various stressors affecting the sampled students' population, and the coping strategies employed. The most predominant stressors in our study were theory and practical examinations (both mid-sem and final); viva-voce; familial issues, among the others. Our study instrument was created by modifying few existing study tools (Academic Stressor Scale and the Brief COPE Scale)., ${ }^{9,10}$ These instruments have been used extensively, with huge success in many countries to evaluate students' stress levels and their academic performances. We recommend this instrument as valid source for evaluating students' stress levels in the Malaysian scenario. But, we also conclude that effectiveness can be increased manifold by performing this study for longer duration of time.

\section{ABBREVIATIONS USED}

ANOVA: Analysis of variance; SD: Standard Deviation; CGPA: Cumulative Grade Point Average; GPA: Grade Point Average; HROOL: Health-Related Quality of Life; SPSS: Statistical Package for Social Sciences; URTI: Upper Respiratory Tract Infections.

\section{ABOUT AUTHORS}

Aaseer Thamby Sam: Is a Senior Lecturer, Unit of Pharmacy Practice, Faculty of Pharmacy, AIMST University, Malaysia. His research interest is in the areas of drug utilization, KAP studies and community pharmacy.

Subramani Parasuraman: Is a Senior Lecturer, Unit of Pharmacology, Faculty of Pharmacy, AIMST University, Malaysia. His research interest is in the areas of pre-clinical pharmacodynamics and toxicological studies.

Bharathi Muttusamy, Sum Mun Yee and Thineswary Ayapanaido: Are currently final year B.Pharm (Hons.) students, who were actively involved in the methodology, field work, results analyses in this work. They are interested in research involving pharmacy practice.

\section{REFERENCES}

1. American Institute of Stress, Definition of Stress. 2012. Available from: http:// www.stress.org/Definition of stress.htm [Last accessed on 03/05/2015]

2. Beck DL, Hacket MB, Srivastava R, McKim E, Rockwell B. Perceived level and sources of stress in university professional schools. J Nurs Educ. 1997;36(4):180-6.

3. Larson EA. Stress in the lives of college women: "lots to do and not much time". J Adolesc Res. 2006;21(6):579-606.

4. Misra R, Castillo L. Academic stress among college students: comparison of american and international students. Int J Stress Manag. 2004;11(2):132-48.

5. Andrews B, Wilding JM. The relation of depression and anxiety to life-stress and achievement in students. Br J Psychol. 2004;95(4):509-21.

6. Heins M, Fahey SN, Leiden LI. Perceived stress in medical, law, and graduate students. J Med Educ. 1984;59(3):169-79.

7. Konduri N, Gupchup GV, Borrego ME, Worley-ouis M. Assessment of the reliability and validity of a stress questionnaire for pharmacy administration graduate students. College Student.J. 2006;40(1):78-90

8. Heffner KL. Neuroendocrine effects of stress on immunity in the elderly: implications for inflammatory disease. ImmunolAllergy Clin North Am. 2011;31 (1):95-108.

9. Kohn JP, Frazer GH. An academic stress scale: identification and rated importance of academic stressors. Psychol Rep.1986;59(2):415-26.

10. Brief COPE. Available at http://www.psy.miami.edu/faculty/ccarver/sclBrCOPE. html [Accessed on 03/11/2015].

11. Spielberger SD. Manual for the State-Trait Anxiety Inventory(Form Y), Consulting Psychologists Press, Palo Alto, Calif,USA; 1983.

12. Dyrbye LN, Thomas MR, Massje FS, Power DV, Eacker A, Harper W. Burnout and suicidal ideation among US medical students. Ann Intern Med. 2008; 149(5):334-41.

13. Dyrbye LN, Thomas MR, Harper W, Massie FS Jr, Power DV, Eacker A The learning environment and medical student burnout: a multicentre study. J Med Educ. 2009;43(3):274-82. 
14. Oppenheimer BT. Short-term small group intervention for college freshmen. J Couns Psychol.1984;31(1):45-53.

15. Khanfer R, Phillips AC, Carroll D, Lord JM. Altered human neutrophil function in response to acute psychological stress. Psychosom Med. 2010;72(7):63640.

16. Zhang J, Li L, Lu Q, Xiao R, Wen H, Yan K. Acute stress enhances contact dermatitis by promoting nuclear factor-kappaB DNA-binding activity and interleukin-18 expression in mice. J Dermatol. 2010;37(6):512-21.
17. Sloan RP, Bagiella E. Claims about religious involvement and health outcomes. Ann Behav Med. 2002;24(1):14-21.

18. Henning K, Ey S, Shaw D. Perfectionism, the imposter phenomenon and psychological adjustment in medical, dental, nursing, and pharmacy students. Med Educ. 1998;32(5):456-64.

19. Gupchup GV, Borrego ME, Konduri N. The impact of student life stress on health related quality of life among doctor of pharmacy students. College Student J. 2004;38(2):292-301 